\title{
Competition between Lythrum salicaria and a rare species: combining evidence from experiments and long-term monitoring
}

\author{
Madlen Denoth · Judith H. Myers
}

Received: 25 April 2006/ Accepted: 23 October 2006/Published online: 23 November 2006

(C) Springer Science+Business Media B.V. 2006

\begin{abstract}
The rare endemic plant Sidalcea hendersonii (Henderson's checker-mallow) occurs in tidal marshes of the Pacific Northwest and may be threatened by Lythrum salicaria (purple loosestrife), a European invader plant. We compared the abundances of Lythrum and Sidalcea in a wetland in British Columbia (Canada) in 1999 to those measured in 1979 to track changes in both species. Although the frequency of Sidalcea decreased by more than $50 \%$, and that of Lythrum increased by almost $20 \%$, there was no significant relationship between the changes of the two species. We assessed the potential effects of competition by Lythrum on Sidalcea in field and patio experiments. In the field, we measured the response of Sidalcea to the removal of Lythrum over a two-year period and compared this to the response of Sidalcea to the removal of native species and in unmanipulated control plots.
\end{abstract}

M. Denoth $(\bowtie) \cdot$ J. H. Myers

Department of Zoology, The University of British Columbia, 6270 University Boulevard, Vancouver, BC, Canada V6T 1 Z4

e-mail: madlen.denoth@unifr.ch

J. H. Myers

e-mail: myers@zoology.ubc.ca

Present Address:

M. Denoth

Département de biologie, Unité d'écologie et évolution, Université de Fribourg, Chemin du

Musée 10, 1700 Fribourg, Switzerland
Removal of Lythrum significantly improved the vegetative performance of Sidalcea compared to the removal of randomly selected native plants and the control treatment in the first year. In the second year, the performance of Sidealcea did not differ significantly with treatment. Removals did not influence the reproductive performance of Sidalcea in either year. A one-year additive experiment, carried out in pots, compared the competitive effect of Lythrum on Sidalcea with that of two native species. Lythrum's impact on Sidalcea was not consistently stronger than that of the native species. Collectively, these results do not indicate a strong impact of Lythrum on the reproduction or abundance of Sidalcea.

Keywords Invasive plant - Purple loosestrife . Removal experiment - Sidalcea hendersonii . Tidal wetland

\section{Introduction}

The ecological and economic impacts of invasive species have been widely documented in terms of their detrimental effects on native ecosystem processes, communities and populations (Vitousek et al. 1996; Mack et al. 2000). Invasive plants could be particularly detrimental to rare and endemic species with small geographic ranges and population sizes, and high ecological specializations. 
However, it has been pointed out that the detrimental effect of invasive species may be exaggerated (Gurevitch and Padilla 2004) due to the failure to disentangle the often simultaneous effects of species invasions and other problems, such as habitat destruction, exploitation, pollution, inbreeding, pollen limitation and herbivory (e.g., Kery and Matthies 2004; Lavergne et al. 2005). To date, only few studies have quantified the effects of invasive species on rare native species (but see Walck et al. 1999; Thomson 2005).

Sidalcea hendersonii S. Wats., Henderson's checker-mallow (henceforth Sidalcea) is native to wet meadows and tidal marshes from southeastern Alaska to northwestern Oregon. The majority of populations occur in Washington state, with a few outlying occurrences in Oregon, British Columbia and Alaska (NatureServe 2005). Only 21-100 scattered populations of the plant persist, and the species is therefore vulnerable to extirpation or extinction across its range (NatureServe 2005). In a recent survey, $90 \%$ of the previously located populations in Oregon could not be refound (NatureServe 2005). Human encroachment into wetlands and displacement by Lythrum salicaria L., purple loosestrife (henceforth Lythrum), a European invader plant, are thought to contribute to the species' rarity (Marshall 1998). However, the actual causes of the species' decline are unknown.

Only two large populations ( $>1,000$ individuals) of Sidalcea are known from southwestern British Columbia: one is at a tidal site near Duncan on Vancouver Island, where Lythrum does not occur, and the other is in Ladner marsh $\left(49^{\circ} 6^{\prime} \mathrm{N}, 123^{\circ} 5^{\prime} \mathrm{W}\right)$, a tidal wetland along the Fraser River (Marshall 1998). The water in Ladner marsh is mostly fresh except in the winter, when brackish water may enter the marsh due to the low discharge rate of the Fraser River. Tidal water levels may vary by up to $3 \mathrm{~m}$ during the growing season from May to September (Bradfield and Porter 1982). Fifty-five vascular plant species, mostly forbs and grasses, occur in Ladner marsh, and among them is Lythrum, which has invaded the wetland before 1979 (Bradfield and Porter 1982); in some areas, the vegetation consists of high-density patches of the invader plant.
Lythrum is thought to be a strong competitor due to its high total biomass, tall plant size, and fast growth (e.g., Gaudet and Keddy 1988; Farnsworth and Ellis 2001), and the rapid spread and high abundance of Lythrum in many invaded areas have led to concerns that the plant may outcompete native plant species and degrade the value of infested areas for wildlife (e.g., Mal et al. 1997; Weihe and Neely 1997; Blossey et al. 2001). Consequently, a biological control program against Lythrum was initiated in North America in the 1990s (Malecki et al. 1993). While there is evidence that the progam is successful in many circumstances, the tidal conditions in Ladner marsh prevent the establishment of the most promising biological control organism, the leaffeeding, chrysomelid beetle Galerucella calmariensis L. (Denoth and Myers 2005).

The aim of this study was to measure the impact of Lythrum on Sidalcea in Ladner marsh in order to assess the risk posed by the invader on the rare plant, and to evaluate the need for efficient control measures. Our approach was three-tiered: First, we determined whether the abundance of Lythrum had increased and was accompanied by a decline of Sidalcea over a 20 -year period in Ladner marsh; data from a previous study in Ladner marsh (Bradfield and Porter 1982) allowed a comparison of the abundance of the invader and the native species in 1979 and in 1999. Second, we measured the ability of Lythrum to suppress Sidalcea relative to co-occurring, native species in Ladner marsh through a removal experiment. Third, we carried out a competition experiment with an additive design to evaluate the impact on Sidalcea growth and reproduction of the exotic species compared to that of two native species. The latter was done since removal experiments may result in biased measures of competition if strong competition has led to spatial segregation of the competitors (Freckleton and Watkinson 2000).

\section{Materials and methods}

Natural history of Sidalcea

Sidalcea can grow conspicuously tall, reaching $1.5 \mathrm{~m}$ in height, and can produce multiple stems 
with inflorescences in the first year. The plant is gynodioecious, with both hermaphroditic, selfcompatible flowers, and female flowers (Marshall and Ganders 2001). Individuals flower from June through September and are pollinated by a variety of insects, including bumblebees and bees (Marshall 1998). In 1995 and 1996, Marshall and Ganders (2001) found that more than $20 \%$ of the yearly seed production was consumed by two specialized weevils: by Macrorhoptus sidalcea Sleeper in Ladner marsh, and by Anthonomus melancholicus Dietz in Duncan, respectively.

Densities of Lythrum and Sidalcea in Ladner marsh in 1979 and 1999

In 1999, we estimated the abundance of Lythrum and Sidalcea, following the methodology of Bradfield and Porter (1982). We recorded the presence and the ground cover of the two species in $1001-\mathrm{m}^{2}$ quadrats in seven transects, which we laid out in approximately the same areas of the wetland as in the previous study (see Fig. 1 in Bradfield and Porter 1982). We compared the average frequencies of Lythrum and Sidalcea in the seven transects between years by permutation tests (Lunneborg 2000) that analyze the outcome of paired $t$-tests. We also performed a permutation test to assess the relationship (Pearson correlation) between changes in frequencies of the two species in the seven transects. We performed both analyses using the software Resampling, which is available at the website: http://www.uvm.edu/ dhowell/StatPages/Resampling/Resampling.html. The number of iterations was 10,000 .

\section{Competitor removal experiment in Ladner marsh}

\section{Experimental design}

Experimental plots were $1 \mathrm{~m}^{2}$ and contained both Lythrum and Sidalcea. To maximize treatment effects, we deliberately chose plots that contained a relatively high abundance of Lythrum. On average, Lythrum abundance at the onset of the experiment was $1,913 \pm 238 \mathrm{~cm}($ mean $\pm \mathrm{SEM})$ of shoot length per plot.
We applied three treatments: In the control treatment, we carried out no manipulation; in the Lythrum removal treatment, we killed all Lythrum plants; and in the native-removal treatment, we killed randomly chosen native plants, but not Lythrum, to compare the responses to removal of Lythrum to that of the removal of native species. We used a randomized complete block design with nine blocks, totaling 27 experimental plots. We established the blocks in eight different areas of the marsh that were at least $100 \mathrm{~m}$ apart. Plots within blocks were separated by at least $5 \mathrm{~m}$.

To remove plants, we wiped all leaves of shoots selected for removal once with Round-up ${ }^{\circledR}$, a systemic, non-selective herbicide in July of 2000 only. Round-up ${ }^{\circledR}$ kills the root system, thereby reducing both above- and below-ground competition. In the native-removal treatment, we wiped one shoot of a native plant with Round-up ${ }^{\circledR}$ for every shoot of Lythrum present in the plot. To imitate the spatial pattern of Lythrum in the plots, we only selected shoots of native species adjacent
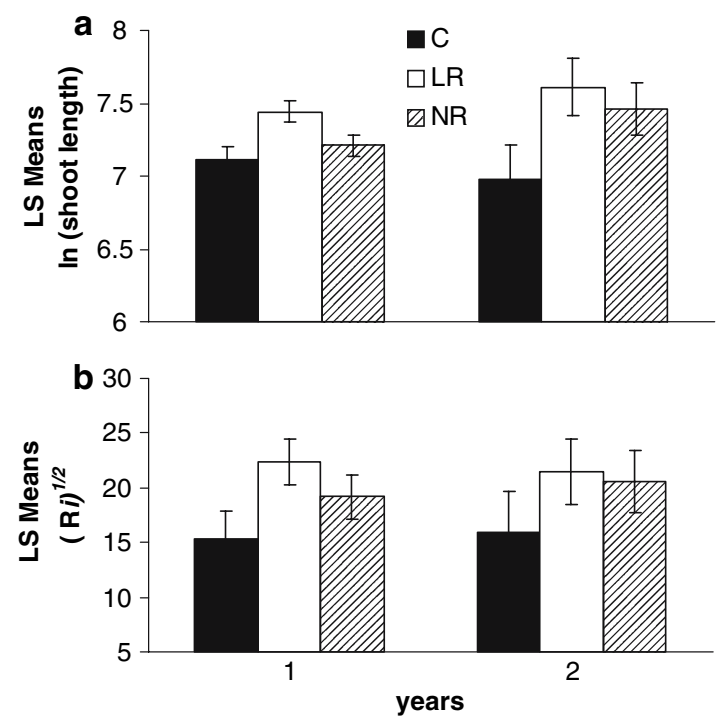

Fig. 1 Sidalcea (a) vegetative performance (ln shoot length \pm SEM) and (b) reproductive performance (index $\left.\left(R_{i}\right)^{1 / 2} \pm \mathrm{SEM}\right)$ by treatment in year 1 and year 2 of the field experiment. Treatments are defined as follows: C, control; LR, Lythrum removal; NR, Native plant removal; Sidalcea vegetative performance differed significantly between LR and the other treatments in year 1 , but not in year 2; Sidalcea reproductive performance did not differ significantly between treatments in either year 
to Lythrum shoots. The native species we removed were mostly herbs and grasses, and occasionally also shrubs of the genus Salix. Most of these species were smaller than Lythrum, which reached an average height of $115 \pm 2 \mathrm{~cm}$ (mean \pm SEM) at the time of the removal. A $95 \%$ reduction of Lythrum in year 1 and a $98.5 \%$ reduction in year 2 showed that the exotic plant was effectively removed from the treated plots. Lythrum plants did not resprout or recolonize from the seedbank.

In July of 2000, prior to experimental treatments, we recorded the total shoot length of Sidalcea in each plot. In August of 2001 (year 1) and June of 2002 (year 2), we recorded the following variables of Sidalcea performance in each plot: total shoot length; average length of the inflorescences of the five tallest shoots; and total number of inflorescences. In 2002, we harvested the above-ground biomass of Lythrum in control and native-removal plots, and that of Sidalcea in all plots and dried it to constant weight at $70^{\circ} \mathrm{C}$.

\section{Statistical analysis}

Since the error structure varied between years, we analyzed the performance of the target plant separately in each year, using analysis of covariance (ANCOVA) with treatment, block and Sidalcea and Lythrum total shoot lengths (covariates) at the onset of the experiment as factors. The shoot lengths (ln transformed) of both species were significantly correlated with their dry biomass (ln transformed) in 2002 (Lythrum: $r=0.96, \quad n=21, \quad P<0.001$, Sidalcea: $r=0.92$, $n=26, P<0.001$ ), and we used them as measures of above-ground biomass in both analyses.

We considered two responses, vegetative and reproductive performance and used Sidalcea total shoot length (ln transformed) as a measure of vegetative performance and the index $R_{i}$, where $R_{i}=n_{i} \cdot l_{i}$, with $n_{i}=$ number of inflorescences in the $i$ th experimental plot, and $l_{i}=$ average length of the inflorescences of the five tallest Sidalcea shoots in the $i$ th experimental plot, as a proxy for the reproductive performance of Sidalcea. $R_{i}$ (square root transformed) was closely correlated with the dry biomass of the inflorescence of Sidalcea in 2002 (ln transformed) after we removed one outlier from the data $(r=0.92$, $n=25, P<0.001)$.

We excluded data from two plots from the analysis: In one plot, the herbicide application damaged the Sidalcea plants, and in one control plot the Sidalcea plants disappeared completely, resulting in an outlier with increased residual variation. Thus, we analyzed responses from a total of 25 plots. Except where noted otherwise, we used the software package JMP 4.0 (SAS Institute, Cary, NC, USA) for all statistical analyses of this work.

Additive competition experiment in plant pots

\section{Experimental design}

The experimental design was additive, with one Sidalcea individual as target plant, grown together with or without competitors, following the design of Keddy et al. (2000). We compared the competitive effect of Lythrum on Sidalcea with that of two perennial, native competitor species: Salix lasiandra Beth., Pacific willow (henceforth Salix), a shrub that grows up to $150 \mathrm{~cm}$ in the marsh, and Oenanthe sarmentosa Presl, Pacific water parsley (henceforth Oenanthe), a low-growing, leafy forb. All competitor species are commonly found in Ladner marsh. We grew Sidalcea plants from seed, and Salix and Lythrum plants from cuttings in the greenhouse; Oenanthe seedlings were collected in the marsh.

When all plants had well-established roots, we arbitrarily selected individual Sidalcea seedlings, ranging in size from the two- to five-leaf stage, placed them in the centers of $4 \mathrm{~L}$ plant pots, and surrounded them by a circle of competitors. To create a range of competitor biomass, we surrounded one Sidalcea individual by zero (control to establish the efficacy of the treatment), two, four, six, eight, or 11 individuals of one competitor species. To prevent the plants from growing outside their pots, we encircled each pot by chicken wire up to $50 \mathrm{~cm}$ in height. All pots received a $120 \mathrm{ppm}$ nutrient solution of Peters Excel 15-5-15 Cal Mag ${ }^{\circledR}$ on a daily basis.

We used five replicate pots per treatment combination of species and density, which resulted in a total of 25 pots per competitor species; 
for Oenanthe, we set up two additional pots. On June 1, 2000, we placed the pots in an open wooden frame on the patio of the horticulture greenhouse of the University of British Columbia. Pot positions were completely randomized.

The experiment lasted until June of 2001. In August of 2000 (year 1), we estimated plant performance through a non-destructive method of recording the total number of leaves on each plant. Most target plants flowered in the first summer, and we counted the number of inflorescences as a measure of reproductive performance. After plant senescence in year 1, we harvested the above-ground biomass of all species and dried it to constant weight at $70^{\circ} \mathrm{C}$. The plants were left on the patio over the winter. In June of 2001 (year 2 ), we estimated plant performance again by the same parameters as in year 1 .

\section{Statistical analysis}

We analyzed the responses in year 1 and year 2 separately because mortality would have reduced statistical power. We did not consider the control treatment in the statistical analysis since the performance of the target plant does not depend on a competitor species when grown alone.

The number of Sidalcea leaves was highly correlated with its above-ground dry biomass in both years (year 1: Spearman's rho $=0.81, n=70$, $P<0.001$; year 2: Spearman's rho $=0.88, n=50$, $P<0.001$ ), and was, in this experiment, a better surrogate for above-ground biomass than shoot length. We used the number of leaves as a measure of vegetative plant performance since it was measured consistently before plant senescence each year. In year 1 , five target plants died and were eliminated from the analysis, and one outlier was removed from the data. In total, we included 71 target plants in the analysis, 24 in the Lythrum treatment, 24 in the Oenanthe treatment, and 23 in the Salix treatment. We analyzed the data with analysis of covariance (ANCOVA) with competitor, competitor dry biomass (covariate), and an interaction term as factors. When we found a significant interaction term, we analyzed regions of significant differences between lines according to the post hoc procedure described by Wilcox (1987) with the help of the computer program WILCOX.EXE, which is available at the website: http://www.zoology.unimelb.edu.au/qkstats/ software.html.

Overwinter mortality of Sidalcea and competitor species, and disturbance by wildlife resulted in a total of 52 target plants available for the analysis in year 2: 15 in the Lythrum treatment, 18 in the Oenanthe treatment, and 19 in the Salix treatment. Since the ranges of the covariate of Lythrum and the native species overlapped little, the use of ANCOVA was inappropriate. Instead, we analyzed the dry biomass of the competitors and the performance of Sidalcea separately, using two single-factor ANOVAs with competitor species as the treatment factor. We analyzed significant differences further with Tukey tests.

\section{Results}

Densities of Lythrum and Sidalcea in Ladner marsh in 1979 and 1999

In 1979, Lythrum was recorded in 31 of 100 quadrats. Although not statistically significant, the frequency increased by $19 \%$ to 37 quadrats in 1999 (permutation test, right tail: $P=0.15$ ) as did the ground cover from $7.9 \pm 1.6 \%$ to $8.6 \pm 1.5 \%$ (permutation test, right tail: $P=0.18$ ). The frequency of Sidalcea decreased by 53\% from 15 to seven quadrats (permutation test, right tail: $P=0.15)$, and the ground cover of the species decreased from $2.7 \pm 0.9 \%$ to $2.1 \pm 0.9 \%$ (permutation test, right tail: $P=0.40)$. The two species co-occurred in only two (1979) and one (1999) quadrats, respectively. There was no significant correlation between the changes in frequency of the two species in the seven transects (permutation test: $P=0.57$ ).

Competitor removal experiment in Ladner marsh

Treatment affected the vegetative performance of Sidalcea in year 1 (Fig. 1a; $F_{12,24}=11.72$, $P<0.01)$. Using linear contrasts, we found that the vegetative growth of Sidalcea was better in the Lythrum removal treatment than in both the native-removal treatment $\left(F_{1,24}=6.15, P<0.03\right)$ 
and the control $\left(F_{1,24}=6.95, P<0.02\right)$. Sidalcea's vegetative performance in year 2 (Fig. $1 \mathrm{a} ; F_{12}$, $\left.{ }_{24}=1.41, P=0.28\right)$ and its reproductive performance in either year (Fig. 1b; year $1: F_{12,24}=2.34$, $P=0.08$; year $\left.2: F_{12,24}=1.65, P=0.20\right)$ were not affected by treatment. The total shoot length of Sidalcea at the onset of the experiment $(P<0.01$ in all analyses), but not that of Lythrum $(P>0.18$ in all analyses), had a highly significant effect on all measures of its own performance in both years.

\section{Additive competition experiment in plant pots}

In year 1, Sidalcea individuals produced, on average, $72 \%$ more leaves and five times more inflorescences in the control treatment than in all other treatments combined. Seventy-two percent of Sidalcea individuals grown with competitors flowered in the first year. Competitor species, competitor dry biomass, and their interaction had all significant effects on the vegetative performance of Sidalcea (Table 1; Fig. 2a; $F_{5,70}=8.43$, $P<0.01)$. The analysis of the interaction revealed that the effect of Lythrum was stronger than that of Salix, but did not differ significantly from that of Oenanthe, over the whole range of the covariate. Oenanthe suppressed the growth of Sidalcea more than Salix only at low levels of dry biomass.

In year 2, the average number of leaves of Sidalcea almost doubled, indicating increased vigor of the surviving plants in the second year

Table 1 ANCOVA of competitor, dry biomass of competitor, and their interaction on Sidalcea leaves in year 1 of the pot experiment. Dry biomass is ln transformed, Sidalcea leaves is square root transformed

\begin{tabular}{lrrrr}
\hline Source of variation & df & SS & \multicolumn{1}{c}{$F$} & \multicolumn{1}{c}{$P$} \\
\hline Competitor & 2 & 27.99 & 18.39 & $<0.01$ \\
ln (dry biomass competitor) & 1 & 7.05 & 9.26 & $<0.01$ \\
Competitor $\times$ ln (dry biomass & 2 & 6.49 & 4.26 & 0.02 \\
$\quad$ competitor) & & & & \\
Error & 65 & 49.46 & &
\end{tabular}

Wilcox pairwise comparisons of treatments. The range of the covariate for which there are significant differences between treatments $(P<0.05)$ is shown in parentheses, if differences are not significant over the whole range:

Lythrum $>$ Salix

Lythrum = Oenanthe

Oenanthe $>$ Salix $(2.70<\ln$ dry biomass $>3.10)$
(Fig. 2b; paired $t$-test, $t_{14}=5.14, \quad P<0.01$ ). Sidalcea plants in the control treatment produced $53 \%$ more leaves than in all other treatments combined. The average dry biomass of Lythrum $(30.5 \pm 2.56 \mathrm{~g})$ significantly exceeded that of both Oenanthe $(7.93 \pm 2.33 \mathrm{~g})$ and Salix (11.31 \pm $2.27 \mathrm{~g})$ (ln-transformed data; $F_{2}, \quad 51=12.56$, $P<0.01$; Tukey $P<0.05)$. Target plant performance varied with competitor species (ln-transformed data; $\left.F_{2,51}=3.38, P=0.04\right)$, and its mean dry biomass was significantly higher when grown with Lythrum as compared to Oenanthe (Tukey $P<0.05)$ despite the four-fold greater biomass of Lythrum. The competitive effect of Salix did not differ from that of either of the two other competitors (Tukey $P>0.05$ ).

\section{Discussion}

Collectively, our results suggest that Lythrum does not have a strong detrimental effect on

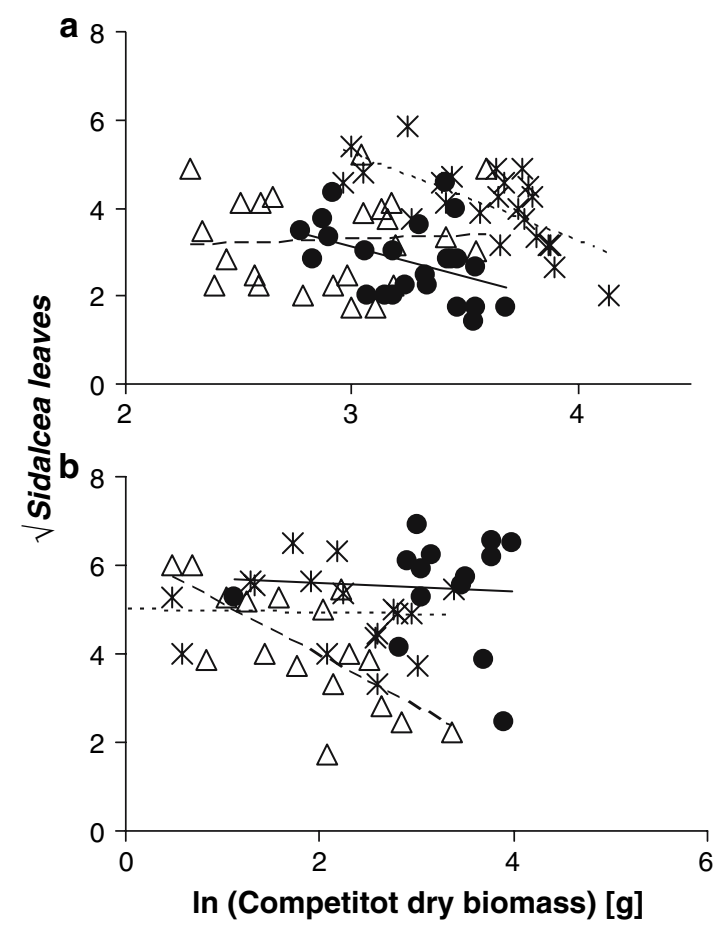

Fig. 2 Sidalcea vegetative performance measured as $\sqrt{ }$ leaves by $\ln$ (competitor dry biomass) in (a) year 1 and (b) year 2 of the pot experiment. Oenanthe, triangles with long-dashed line; Salix, asterisks with short-dashed line; Lythrum, filled circles with solid line 
Sidalcea in Ladner marsh. The sampling study in the marsh indicates that Sidalcea did not decrease significantly during the 20-year period, nor was there evidence for a relationship between the changes in frequency of Sidalcea and Lythrum. Although Lythrum has been reported to be able to rapidly produce monospecific stands (Thompson et al. 1987), this is clearly not the case everywhere in Ladner marsh: the overall ground cover of the invader was less than $10 \%$, both in 1979 and 1999. Since human influence is limited in Ladner marsh, tidal disturbances, and interactions with a multitude of native competitors appear to restrict the ability of the invader to dominate in all areas. While this tidal marsh may not be representative of a majority of invaded wetlands, our findings are consistent with those from several Minnesota wetlands (Hager and Vinebrooke 2004).

Both competition experiments produced similar results, indicating that the competitive effect of Lythrum is not consistently stronger than that of native species, despite differences in a variety of factors, such as the experimental design (additive versus removal), environmental conditions (field versus pots) and competing species (two versus multiple). At least two factors may be responsible for these results. First, Sidalcea possesses strong competitive abilities, and second, at least in the early stages of the competition process, the tested native species show an equal or higher ability to suppress Sidalcea than Lythrum. This is consistent with the findings of other studies that alien invaders do not necessarily have a higher competitive ability than native plants (Daehler 2003; Houlahan and Findlay 2004; Thomson 2005), but the result likely depends on the identity of the native species with which the invader competes.

The response of Sidalcea to the removal of Lythrum was transient when compared to the removal of native plant species. The removal of Lythrum significantly improved the vegetative performance of Sidalcea in the first year, but not in the second, which suggests that the resources that became available with Lythrum removal were depleted by the competing plant community in year 2. The reproductive output of Sidalcea was not influenced by the treatments in either year, indicating that Sidalcea did not achieve a significant, continued fitness benefit from the removal of vegetation. The initial abundance of Sidalcea itself explained most of the variation in the performance of the target plant in both years. This likely reflects the growth and perennial lifestyle of Sidalcea individuals: new shoots arise from existing plants, and apparently, the average annual mortality of Sidalcea is low.

Competition is expected to be more intense under conditions of reduced herbivory and disturbance, and thus, if competition cannot be shown under greenhouse conditions, it is unlikely to be important in nature (Gibson et al. 1999). Indeed, Lythrum had a more severe effect on Sidalcea than the native Salix in the pot experiment in year 1 . However, Oenanthe and Lythrum did not differ significantly in their competitive effects, and overall Sidalcea survival was similar when grown with different competitors. A possible, lower reproductive success of Sidalcea in the first year when grown with Lythrum is likely small compared to the lifetime reproductive output of a long-lived perennial. In year 2, Lythrum's effect on Sidalcea did not differ from that of Salix, and was less detrimental than that of the native Oenanthe. This is surprising, given that the above-ground biomass of Lythrum greatly exceeded that of both native competitors. We speculate that this result was due to Sidalcea's early emergence in February of year 2 (Denoth 2004) and its tall growth, which likely reduced the influence of the competitors by allowing the rare plant ample access to light, a potentially limiting factor in wetlands (Keddy 2000). However, it is possible that a longer duration of the competition experiments would have changed their outcome; for example, Mal et al. (1997) found that the dominance of the competing species changed significantly over time: only in the fourth year of their experiment was Lythrum the dominant competitor.

Despite Sidalcea's strong competitive abilities, however, its abundance declined by over $50 \%$ in the 20-year interval. Although not statistically significant, the decline could indicate that the persistence of Sidalcea in Ladner marsh is threatened. The plant's gynodioecious breeding system, inbreeding, the presence of a specialized 
seed predator, and interactions with soil pathogens (Klironomos 2002) could all contribute to its rarity and the observed lack in performance increase after the localized removal of Lyhtrum. Moreover, we cannot exclude the possibility of negative, indirect effects on Sidalcea by Lythrum. Since both plant species flower synchronously, possess a similar flower color, and share pollinators, there may be indirect interactions with negative fitness effects. Lythrum may compete with Sidalcea for pollinating insects, and a possible transfer of pollen between the two species could inhibit ovule fertilization. In fact, casual sampling in 1999 suggested a low seed set of Sidalcea in Ladner marsh, while the seed production in the population on Vancouver Island, where Lythrum has not invaded, was plentiful. Significant negative effects of Lythrum on plant pollination and seed set in the field were found in several native species (Grabas and Laverty 1999; Brown and Mitchell 2001; Brown et al. 2002), and further work might consider if pollinator-mediated competition with Lythrum occurs. Based on the results of this work, however, employing control methods for Lythrum in Ladner marsh is not warranted.

Acknowledgements We thank Gary Bradfield for his help and for providing his data; our field assistants Janis Newhouse and Jennifer Passmore; David Kaplan for his invaluable help in the greenhouse; Charles Gates, Diane Srivastava, Mohammed Khan and Dolph Schluter for their help with the statistical analyses; five anonymous reviewers and Heather Hager for their advice, which greatly improved earlier versions of this paper; Fritz Denoth for his support throughout this project. Financial aid was provided by BC Hydro, the City of Langley, the Habitat Conservation Trust Fund, the Integrated Vegetation Management Association of British Columbia, Mountain Equipment Co-op, the Natural Sciences and Engineering Research Council (NSERC) of Canada, the Shell Environmental Fund, VanCity Langley, and WWF-Endangered Species Recovery Fund.

\section{References}

Blossey B, Skinner LC, Taylor J (2001) Impact and management of purple loosestrife (Lythrum salicaria) in North America. Biodivers Conserv 10:1787-1807

Bradfield GE, Porter GL (1982) Vegetation structure and diversity components of a Fraser estuary tidal marsh. Can J Bot 60:440-451
Brown BJ, Mitchell RJ (2001) Competition for pollination: effects of pollen of an invasive plant on seed set of a native congener. Oecologia 129:43-49

Brown BJ, Mitchell RJ, Graham SA (2002) Competition for pollination between an invasive species (purple loosestrife) and a native congener. Ecology 83:23282336

Daehler CC (2003) Performance comparisons of cooccurring native and alien invasive plants: implications for conservation and restoration. Annu Rev Ecol Evol Syst 34:183-211

Denoth M (2004) Impact and biological control of Lythrum salicaria in southwestern British Columbia. Dissertation, The University of British Columbia

Denoth M, Myers JH (2005) Variable success of biological control of Lythrum salicaria in British Columbia. Biol Control 32:269-279

Farnsworth EJ, Ellis DR (2001) Is purple loosestrife (Lythrum salicaria) an invasive threat to freshwater wetlands? Conflicting evidence from several ecological metrics. Wetlands 21:199-209

Freckleton RP, Watkinson AR (2000) On detecting and measuring competition in spatially structured plant communities. Ecol Lett 3:423-432

Gaudet CL, Keddy PA (1988) A comparative approach to predicting competitive abilities from plant traits. Nature 334:242-243

Gibson DJ, Connolly J, Hartnett DC et al (1999) Designs for greenhouse studies of interactions between plants. J Ecol 87:1-16

Grabas GP, Laverty TM (1999) The effect of purple loosestrife (Lythrum salicaria L.; Lythraceae) on the pollination and reproductive success of sympatric coflowering wetland plants. Ecoscience 6:230-242

Gurevitch J, Padilla DK (2004) Are invasive species a major cause of extinctions? Trends Ecol Evol 19:470474

Hager HA, Vinebrooke RD (2004) Positive relationships between invasive purple loosestrife (Lythrum salicaria) and plant species diversity and abundance in Minnesota wetlands. Can J Bot 82:763-773

Houlahan JE, Findlay CS (2004) Effect of invasive plant species on temperate wetland plant diversity. Conserv Biol 18:1132-1138

Keddy PA (2000) Wetland ecology principles and conservation. Cambridge University Press, Cambridge

Keddy P, Gaudet C, Fraser LH (2000) Effects of low and high nutrients on the competitive hierarchy of 26 shoreline plants. J Ecol 88:413-423

Kery M, Matthies D (2004) Reduced fecundity in small populations of the rare plant Gentianopsis ciliate (Gentianaceae). Plant Biol 6:683-688

Klironomos JN (2002) Feedback with soil biota contributes to plant rarity and invasiveness in communities. Nature 417:67-70

Lavergne S, Debussche M, Thompson JD (2005) Limitations on reproductive success in endemic Aquilegia viscosa (Ranunculaceae) relative to its widespread congener Aquilegia vulgaris: the interplay of herbivory and pollination. Oecologia 142:212-220 
Lunneborg CE (2000) Data analysis by resampling: concepts and applications. Duxbury, Pacific Grove

Mack RN, Simberloff D, Lonsdale WM et al (2000) Biotic invasions: causes, epidemiology, global consequences, and control. Ecol Appl 10:689-710

Mal TK, LovettDoust J, LovettDoust L (1997) Timedependent competitive displacement of Typha angustifolia by Lythrum salicaria. Oikos 79:26-33

Malecki RA, Blossey B, Hight SD et al (1993) Biological control of purple loosestrife. Bioscience 43:680-686

Marshall M (1998) The maintenance of gynodioecy in Sidalcea hendersonii. Dissertation, The University of British Columbia

Marshall M, Ganders FR (2001) Sex-biased seed predation and the maintenance of females in a gynodioecious plant. Am J Bot 88:1437-1443

NatureServe (2005) NatureServe explorer: an online encyclopedia of life [web application]. Version 4.4. http://www.natureserve.org/explorer. Cited 8 April 2005

Thompson DQ, Stuckey RL, Thomspson EB (1987) Spread, impact, and control of purple loosestrife (Lythrum salicaria L.) in North American wetlands.
US Fish and Wildlife Service, Washington DC. http:// www.npwrc.usgs.gov/resource/1999/loosstrf/loosstrf.htm. Cited 8 April 2005

Thomson D (2005) Measuring the effects of invasive species on the demography of a rare endemic plant. Biol Invasions 7:615-624

Vitousek PM, Dantonio CM, Loope LL et al (1996) Biological invasions as global environmental change. Am Sci 84:468-478

Walck JL, Baskin JM, Baskin CC (1999) Effects of competition from introduced plants on establishment, survival, growth and reproduction of the rare plant Solidago shortii (Asteraceae). Biol Conserv 88:213219

Weihe PE, Neely RK (1997) The effects of shading on competition between purple loosestrife and broadleaved cattail. Aquat Bot 59:127-138

Wilcox RR (1987) Pairwise comparisons of J independent regression lines over a finite interval, simultaneous pairwise comparison of their parameters, and the Johnson-Neyman procedure. Br J Math Stat Psychol 40:80-93 